\title{
THE EVOLUTION OF CETACEAN FEEDING MECHANISMS
}

HEYNING, John E., Mammalogy, Natural History Museum of Los Angles County, 900 Exposition Blvd., Los Angeles, CA 90007, U.S.A.

The two major groups of extant cetaceans, the baleen whales and toothed whales, differ ecologically and morphologically in how they locate and capture their food. Archaeocetes and the most primitive odontocetes, such as agorophiids and squalodontids, had procumbent conical front teeth and relatively large, closely spaced, sectorial cheekteeth. These teeth appear to be adapted for seizing and cutting larger prey into bite-size pieces. Archaeocetes and other primitive cetaceans had relatively large temporal fossae and zygomatic arches. These structures would have served as the origins for the large temporalis and masseter muscles, and indicate active predation on large prey.

Toothed whales pursue, capture, and swallow single prey items. The morphological adaptations and foraging behavior that have evolved relating to feeding vary greatly among odontocetes. Most modern species have supernumerary and secondarily monodont dentition that is used to pierce and hold fish and/or squid. There is a trend for primarily teuthophagous species to exhibit reduced dentition. These species primarily use suction to capture prey. Suction feeding is correlated with a large hyoid apparatus. For those suction-feeding species that retain teeth, such as the sperm whale and beaked whales, it has been postulated that these teeth serve more in social interactions than for prey acquisition. Most modern odontocetes have extremely reduced zygomatic arches and masseter muscles. The major muscles involved in jaw closure are the somewhat reduced temporalis and the enlarged pterygoideus muscles. This shift in muscular emphasis for jaw closing may be related to the increasing size of the braincase in many odontocete lineages.

The hallmark of mysticete evolution was the development of baleen to filter prey items from the water. Several taxa of primitive cetaceans, such as Kekenodon and Llanocetus, with widely spaced, ornately cusped cheekteeth are suggested to belong to the transition lineage from archaeocetes to mysticetes. All modern mysticetes posses features that allow for varying degrees of jaw kinesis while feeding. The rostra of right whales are highly arched to accommodate the long plates of baleen. With mouths open, they skim the water surface with their long baleen plates exposed, capturing surface-dwelling animal plankton. The rorquals are gulpers. These whales have many grooves extending from their chin back beyond the throat region. These throat grooves act like the pleats of a skirt, allowing the floor of the mouth to billow out like a large sac. Rorqual whales also possess an extremely large temporalis muscle to close the mouth distended by a large volume of water.

Many families of modern odontocetes and mysticetes possess grooves in the gular region. Thus, it is likely that advanced archaeocetes also possessed such grooves. These grooves allow for gular distension. The type of throat groove distention exhibited by gray whales, sperm whales and beaked whales probably differs significantly from that of rorqual whales. In the former groups, it is likely that active contraction of head and throat muscles increases the volume of the oral cavity. In rorquals, the mouth is opened while the whale is swimming and thus water pressure fills the oral cavity. 